Research Article

www.ijrap.net

\title{
AMELIORATION OF HALOPERIDOL-INDUCED OROFACIAL DYSKINESIA AND CATALEPSY BY ELLAGIC ACID IN RATS
}

Dinesh Dhingra *, Nidhi Gahalain

Department of Pharmaceutical Sciences, Guru Jambheshwar University of Science and Technology, Hisar, Haryana, India

Received on: 13/01/16 Revised on: 31/01/16 Accepted on: 09/02/16

\author{
*Corresponding author \\ E-mail: din_dhingra@ rediffmail.com
}

DOI: $10.7897 / 2277-4343.07292$

\begin{abstract}
The aim of the present study was to investigate the effect of ellagic acid on haloperidol-induced orofacial dyskinesia and catalepsy in Wistar male albino rats and to explore the possible underlying mechanisms for these effects. Haloperidol (1 mg/kg, ip) was administered on $21 \mathrm{successive} \mathrm{days} \mathrm{to}$ induce orofacial dyskinesia in rats. Ellagic acid $(10,20$ and $40 \mathrm{mg} / \mathrm{kg}$, po) was administered for 21 successive days to separate groups of haloperidol treated rats. Haloperidol significantly induced orofacial dyskinesia in rats as indicated by increase in vacuous chewing movements and tongue protrusions. It also increased duration of catalepsy and decreased locomotor activity of rats. Ellagic acid significantly reversed haloperidol-induced vacuous chewing movements, tongue protrusions, catalepsy and hypolocomotion in rats and significantly ameliorated haloperidol-induced decrease in brain dopamine and serotonin levels. Ellagic acid significantly attenuated haloperidol-induced orofacial dyskinesia and catalepsy, probably through increase in brain dopamine and serotonin levels. Thus, ellagic acid may be explored further for its potential in the management of neurolepticinduced tardive dyskinesia and Parkinsonism.
\end{abstract}

Key words: Ellagic acid, Haloperidol, Orofacial dyskinesia, Catalepsy

\section{INTRODUCTION}

Tardive dyskinesia is a neurological syndrome resulting from chronic administration of neuroleptics, such as haloperidol; and characterized by repetitive involuntary movements involving bucco-lingual region. Occurrence of tardive dyskinesia is about $20-50 \%$ in patients who are on prolonged antipsychotic medications ${ }^{1}$. Haloperidol, a typical neuroleptic widely used for treatment of schizophrenia, is associated with many neurological and extrapyramidal side effects mainly parkinsonism and tardive dyskinesia ${ }^{2}$. Tardive dyskinesia may be due to increase in oxidative stress and dopamine supersensitivity. Haloperidol is metabolized by an oxidase which generates large quantities of oxyradicals and a toxic pyridinium-like metabolite ${ }^{3}$ and induces oxidative stress ${ }^{4}$. Chronic blockade of dopamine $\mathrm{D}_{2}$ receptors by neuroleptics in nigrostriatal neurones of the brain leads to increase in dopamine turnover in basal ganglia and this may lead to overproduction of free radicals such as dopamine quinone and hydrogen peroxide through the activity of MAO. Tardive dyskinesia is due to a neurotoxic effect of these free radical byproducts from catecholamine metabolism in the basal ganglia ${ }^{5}$. The dopamine supersensitivity hypothesis proposes that antipsychotic drug treatment causes hypersensitization of dopamine $\mathrm{D}_{2}$ receptors, via increased density in all dopaminergic pathways. This disturbs dopamine levels in brain regions responsible for motor symptoms, resulting in motor dysfunction. Classical neuroleptics such as haloperidol remain bound to dopamine $\mathrm{D}_{2}$ receptors and accumulate in brain tissue ${ }^{6}$. This leads to increased density of dopamine $\mathrm{D}_{2}$ receptors and increased uptake of dopamine, especially after withdrawal of antipsychotics, which results in tardive dyskinesia. Various neurotransmitter (dopaminergic, serotonergic, noradrenergic and GABAergic) systems abnormalities have been implicated in the pathophysiology of tardive dyskinesia ${ }^{7}$.
Bioactive compounds possessing antioxidant activity such as quercetin $^{8}$, gallic acid $^{9}$, etc. have been shown to be effective in reversing neuroleptic-induced orofacial dyskinesia in laboratory animals. Vitamin E and melatonin have antioxidant property and been reported to reverse symptoms of tardive dyskinesia in clinical studies ${ }^{10},{ }^{11}$. Thus, substances possessing antioxidant activity may be explored for prevention and treatment of neuroleptic-induced tardive dyskinesia ${ }^{12}$.

Ellagic acid is a naturally occurring polyphenolic compound, present in a number of plants such as Emblica officinalis ${ }^{13}$, Punica granatum ${ }^{14}$ etc. Ellagic acid has been reported to possess neuroprotective ${ }^{15}$, antidepressant ${ }^{16}$, anti-epileptic ${ }^{17}$, antiAlzheimer $^{18}$, anti-amyloid ${ }^{19}$, anti-parkinsonian ${ }^{20}$, anti-anxiety ${ }^{21}$ and antioxidant ${ }^{22}$ activities. Recently, we have reported protective effect of ellagic acid against reserpine-induced orofacial dyskinesia and catalepsy in rats ${ }^{23}$. But the effect of ellagic acid on haloperidol-induced orofacial dyskinesia and catalepsy has not been reported in the literature. So this study was designed to explore the effect of ellagic acid on haloperidolinduced orofacial dyskinesia, catalepsy and hypolocomotion in rats.

\section{MATERIALS AND METHODS}

\section{Experimental animals}

Wistar male albino rats, weighing 100-150 g and 2-3 months age were purchased from Disease Free Small Animal House, Lala Lajpat Rai University of Veterinary and Animal Sciences, Hisar (Haryana, India). Only male rats were used in present study, since estrogens present in female rats have been reported to possess neuroprotective property which may mask development of orofacial dyskinesia ${ }^{24}$. The animals were housed under standard laboratory conditions with 12 hour light-dark cycle. They had free access to food and water. The animals were 
acclimatized to laboratory conditions prior to experimentation. The experiments were carried out between 9:00 and 16:00 h. The experimental protocol was approved by Institutional Animal Ethics Committee [Item no. 4 of the minutes of $26^{\text {th }}$ meeting of IAEC (Endst. No. IAEC/193-201; dated 09-5-2014)]. The animal care was taken as per the guidelines of Committee for the Purpose of Control and Supervision of Experiments on Animals (CPCSEA), Ministry of Environment and Forests, Government of India.

\section{Drugs and chemicals}

Haloperidol (Serenace ${ }^{\circledR}$, RPG Life Sciences Ltd, Mumbai, India), ellagic acid and dopamine hydrochloride (Hi-Media Laboratories Pvt. Ltd., Mumbai, India), serotonin creatinine sulfate monohydrate (Sigma-Aldrich, USA) were used in the present study. All other reagents used were of analytical grade. Haloperidol injection was diluted with distilled water and administered intraperitoneally. Ellagic acid was suspended in $0.1 \% \mathrm{w} / \mathrm{v}$ gum acacia and administered orally. All the drugs were administered in a volume of $0.5 \mathrm{ml}$ per $100 \mathrm{~g}$ of body weight of rats.

\section{Selection of doses}

Doses of various drugs were selected on the basis of literature, i.e., $1 \mathrm{mg} / \mathrm{kg}$ haloperidol ${ }^{25}, 10,20$ and $40 \mathrm{mg} / \mathrm{kg}$ ellagic acid ${ }^{17}$, 26 .

\section{Induction of orofacial dyskinesia}

Haloperidol ( $1 \mathrm{mg} / \mathrm{kg}$, ip) was administered for 21 successive days to induce orofacial dyskinesia. All behavioral assessments were done weekly and last quantification was done after 24 hour of last dose of haloperidol ${ }^{25}$.

\section{Experimental protocol}

The animals were distributed into the following groups, each group having 6 animals:

Groups 1 to 5 ( $\mathrm{n}=6$ each): Vehicle $(0.1 \%$ gum acacia $)$, haloperidol $(1 \mathrm{mg} / \mathrm{kg}, i p)$, ellagic acid $(10,20,40 \mathrm{mg} / \mathrm{kg}, p o)+$ haloperidol $(1 \mathrm{mg} / \mathrm{kg}, i p)$, respectively.

Haloperidol was administered for 21 successive days for induction of oral dyskinesia. Ellagic acid was administered orally for 21 successive days. Haloperidol was administered after $50 \mathrm{~min}$ of ellagic acid administration daily for 21 successive days. Vacuous chewing movements (VCMs) and tongue protrusions were recorded weekly i.e. on $7^{\text {th }}$ and $14^{\text {th }}$ day before ellagic acid administration and on $22^{\text {nd }}$ day $(24 \mathrm{~h}$ after last dose administration of haloperidol). After recording of VCMs and tongue protrusions in animals of group 1 to 5 , they were subjected to behavioral assessment for catalepsy. Animals from group 1 to 5 after behavioral assessment for catalepsy were tested in actophotometer for recording of locomotor activity.

\section{Behavioral models}

\section{Haloperidol-induced VCMs and tongue protrusions}

On test day, rats were individually placed in a small observation cage $\left(20 \times 20 \times 19 \mathrm{~cm}^{3}\right)$ for assessment of orofacial dyskinesia. Animals were given $10 \mathrm{~min}$ to get used to observation cage before behavioral assessments. To quantify the occurrence of orofacial dyskinesia, mirrors were placed under the floor and behind the back wall of the observation cage to permit observations when animal faced away from the observer. The behavioral parameters (VCMs and tongue protrusion) of oral dyskinesia were measured continuously for a period of $5 \mathrm{~min}$. VCMs are defined as single mouth openings in the vertical plane not directed towards physical material. VCMs or tongue protrusion were not taken into account during a period of grooming. Counting was stopped whenever the rat began grooming, and restarted when grooming stopped. In all the experiments, the scorer was unaware of the treatment given to the animals ${ }^{8}$.

\section{Haloperidol-induced catalepsy}

The catalepsy was assessed using 3 and $9 \mathrm{~cm}$ wooden blocks ${ }^{27}$. The following scores were assigned to the rats: rats move normally when placed on table, score 0 ; rats move normally when touched/pushed, score 0.5 ; front paws of rat were placed on $3 \mathrm{~cm}$ block and if it fails to correct the posture in $10 \mathrm{~s}$, a score of 0.5 was assigned to each paw (total 1). If the rat fails to correct the posture within $10 \mathrm{~s}$, when placed on $9 \mathrm{~cm}$ block, score for each paw was 1 (total 2); thus for a single rat maximum score assigned was 3.5 .

\section{Measurement of locomotor activity}

The horizontal locomotor activities of control and test animals were measured for a period of $10 \mathrm{~min}^{27}$ using Medicraft Photoactometer, Model No. 600-6D (INCO, Ambala, India). The locomotor activity was expressed in terms of total photo beam counts/10 min per animal.

\section{Biochemical estimations}

\section{Dissection and homogenization}

After behavioral testing, on day 22, rats were sacrificed by cervical dislocation and forebrain ${ }^{8}$ was dissected out. Dopamine and serotonin levels were estimated by the method of Schlumpf et al. ${ }^{28}$ with slight modifications. The forebrain was weighed and homogenized in $3 \mathrm{ml} \mathrm{HCl}$ - Butanol $(0.85 \mathrm{ml} 37 \% \mathrm{HCl}$ in 1 liter n-butanol) in a cool environment for $1 \mathrm{~min}$. The sample was then centrifuged at $0^{\circ} \mathrm{C}$ for $10 \mathrm{~min}$ at $2000 \mathrm{~g}$ using refrigerated centrifuge (Remi instrument, C-30 plus, Mumbai, India). $0.8 \mathrm{ml}$ of supernatant phase was removed and added to a centrifuge tube containing $2 \mathrm{ml}$ of heptane and $0.25 \mathrm{ml} 0.1 \mathrm{M} \mathrm{HCl}$. After $10 \mathrm{~min}$ of vigorous shaking, the tube was centrifuged under same conditions as in order to separate two phases. Upper organic phase was discarded and the aqueous phase was used for dopamine and serotonin assay.

\section{Estimation of brain dopamine levels}

To $1 \mathrm{ml}$ of the $\mathrm{HCl}$ phase, $0.25 \mathrm{ml} 0.4 \mathrm{M} \mathrm{HCl}$ and $0.5 \mathrm{ml} \mathrm{EDTA} /$ sodium acetate buffer ( $\mathrm{pH}$ 6.9) were added, followed by $0.5 \mathrm{ml}$ iodine solution $(0.1 \mathrm{M}$ in ethanol) for oxidation. The reaction was stopped after $2 \mathrm{~min}$ by the addition of $0.5 \mathrm{ml}$ sodium sulphite in $5 \mathrm{M}$ sodium hydroxide $\left(0.5 \mathrm{~g} \mathrm{Na}_{2} \mathrm{SO}_{3}\right.$ in $2 \mathrm{ml} \mathrm{H}_{2} \mathrm{O}+$ $18 \mathrm{ml} 5 \mathrm{M} \mathrm{NaOH}) .10 \mathrm{M}$ Acetic acid $(0.5 \mathrm{ml})$ was added 1.5 min later. The solution was then heated to $100^{\circ} \mathrm{C}$ for $6 \mathrm{~min}$. When the samples again reach room temperature, fluorescence was read (330 to $375 \mathrm{~nm}$ ) using Systronic photofluorometer (Model 152, Ahmedabad, Gujarat). Compared the tissue values (fluorescence of tissue extract minus fluorescence of tissue blank) with an internal reagent standard (fluorescence of internal reagent standard minus fluorescence of internal reagent blank). Tissue blanks for the assay were prepared by adding the reagents of the oxidation step in reverse order (sodium sulphite before iodine). Internal reagent standards were obtained by adding $500 \mathrm{ng}$ of dopamine hydrochloride in $0.125 \mathrm{ml}$ distilled water and $2.5 \mathrm{ml} \mathrm{HCl}-\mathrm{Butanol}$, which was then carried through the entire extraction procedure. For the internal reagent blank, $0.125 \mathrm{ml}$ water was added to $2.5 \mathrm{ml} \mathrm{HCI-butanol^{28 }}$.

\section{Estimation of brain serotonin levels}

$1.25 \mathrm{ml}$ of o-phthaldialdehyde reagent $(20 \mathrm{mg} \%$ in conc. $\mathrm{HCl}$ ) was added to $1 \mathrm{ml}$ of the aqueous phase (mentioned above under dissection and homogenization). The fluorophore was developed by heating to $100^{\circ} \mathrm{C}$ for $10 \mathrm{~min}$. After the samples reached equilibrium with the ambient temperature, fluorescence or 
intensity readings at 360-470 $\mathrm{nm}$ were taken using Systronic photofluorometer (Model 152, Ahmedabad, Gujarat). Compared the tissue values (fluorescence of tissue extract minus fluorescence of tissue blank) with an internal reagent standard (fluorescence of internal reagent standard minus fluorescence of internal reagent blank). For serotonin tissue blank, 0.025 conc. HCI without o-phthaldialdehyde was added. Internal reagent standard was obtained by adding $500 \mathrm{ng}$ of serotonin creatinine sulfate monohydrate in $0.125 \mathrm{ml}$ distilled water and $2.5 \mathrm{ml} \mathrm{HCl}$ Butanol, which was then carried through the entire extraction procedure. For the internal reagent blank, $0.125 \mathrm{ml}$ distilled

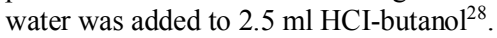

\section{Statistical analysis}

All the results were expressed as mean \pm SEM. Data were analyzed by one-way analysis of variance (ANOVA) followed by Tukey's multiple comparison test using Graph Pad Instat. $p<$ 0.05 was considered as statistically significant.

Table 1: Effect of ellagic acid on haloperidol-induced changes in brain dopamine and serotonin levels

\begin{tabular}{|c|c|c|}
\hline Drug Treatment (mg/kg) & $\begin{array}{c}\text { Dopamine levels (pg/mg) } \\
(\text { mean } \pm \text { SEM) }\end{array}$ & $\begin{array}{c}\text { Serotonin levels (pg/mg) (mean } \pm \\
\text { SEM) }\end{array}$ \\
\hline Vehicle (0.1\% gum acacia) & $919.86 \pm 95.21$ & $1718.75 \pm 124.55$ \\
\hline Haloperidol (1) & $518.67 \pm 40.53^{\mathrm{a}}$ & $952.33 \pm 79.17^{\mathrm{a}}$ \\
\hline Ellagic Acid (10)+ Haloperidol (1) & $906.33 \pm 52.08^{\mathrm{b}}$ & $1526.71 \pm 119.79^{\mathrm{b}}$ \\
\hline Ellagic Acid (20)+ Haloperidol (1) & $938.34 \pm 93.77^{\mathrm{b}}$ & $1826.54 \pm 104.5^{\mathrm{c}}$ \\
\hline Ellagic Acid (40)+ Haloperidol (1) & $1018.69 \pm 54.21^{\mathrm{c}}$ & 10.856 \\
\hline$F(4,25)$ & 7.632 & $<0.05$ \\
\hline p value & $<0.05$ & $72.74^{\mathrm{b}}$ \\
\hline
\end{tabular}

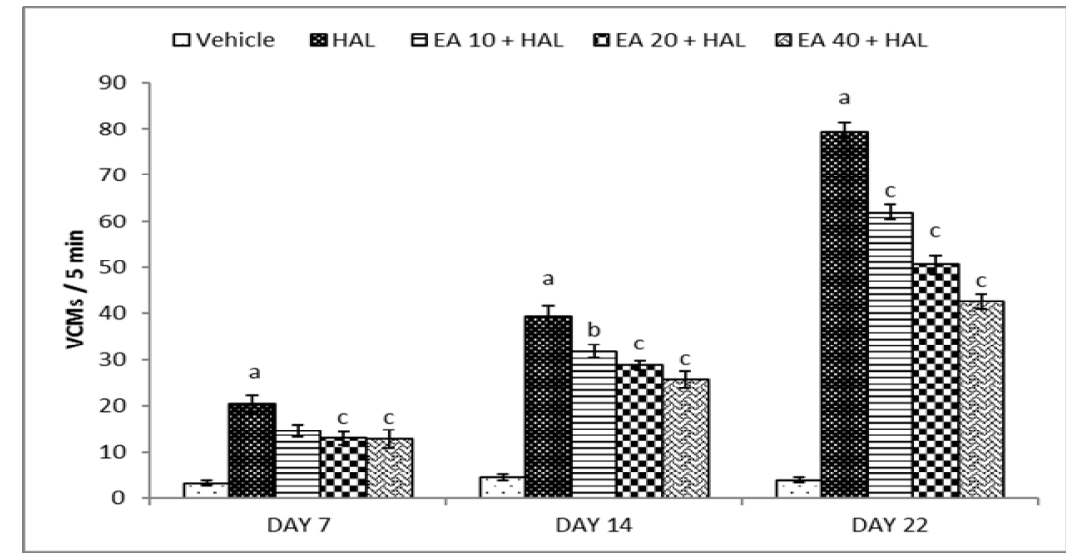

Figure 1: Effect of ellagic acid on haloperidol-induced vacuous chewing movements in rats

$\mathrm{n}=6$ each group. Values are expressed as the mean \pm SEM. Data were analyzed by using one-way ANOVA followed by Tukey's multiple comparison test.

$F(4,25)$, Day 7=17.17; Day 14=70.73; Day 22=266.55. $\mathrm{p}<0.05 .{ }^{\mathrm{a}} \mathrm{p}<0.001$, as compared to vehicle treated control, ${ }^{\mathrm{b}} \mathrm{p}<0.05$ and ${ }^{\mathrm{c}} \mathrm{p}<0.001$ respectively as compared to haloperidol treated group. HAL stands for haloperidol; EA stands for ellagic acid.

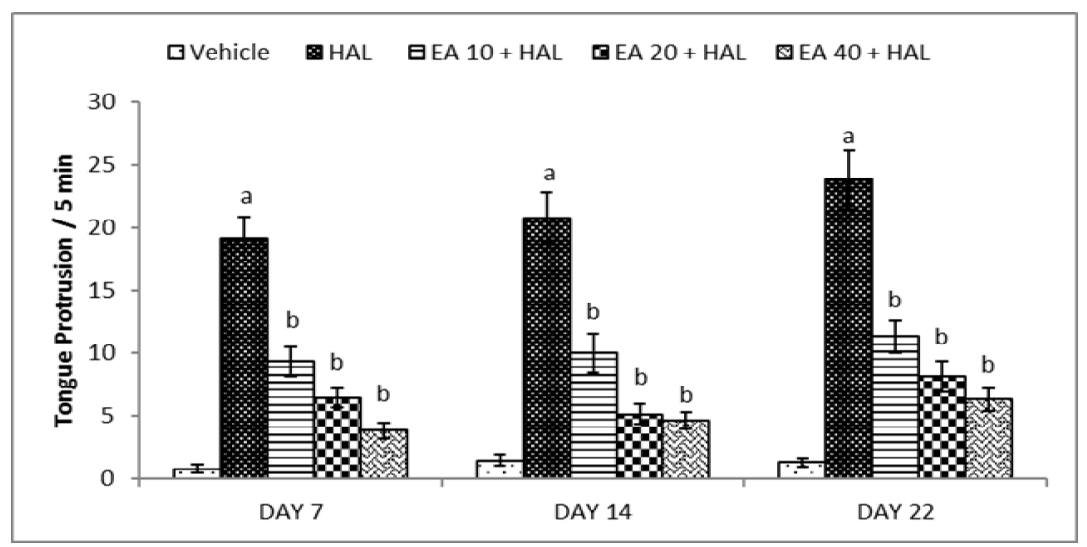

Figure 2: Effect of ellagic acid on haloperidol-induced tongue protrusions in rats

$n=6$ each group. Values are expressed as the mean \pm SEM. Data were analyzed by using one-way ANOVA followed by Tukey's multiple comparison test.

$F(4,25)$, Day 7=45.89; Day 14=37.94; Day 22=38.47. $\mathrm{p}<0.05 .{ }^{\mathrm{a}} \mathrm{p}<0.001$ as compared to vehicle treated control, ${ }^{\mathrm{b}} \mathrm{p}<0.001$ as compared to haloperidol treated group. HAL stands for haloperidol; EA stands for ellagic acid. 


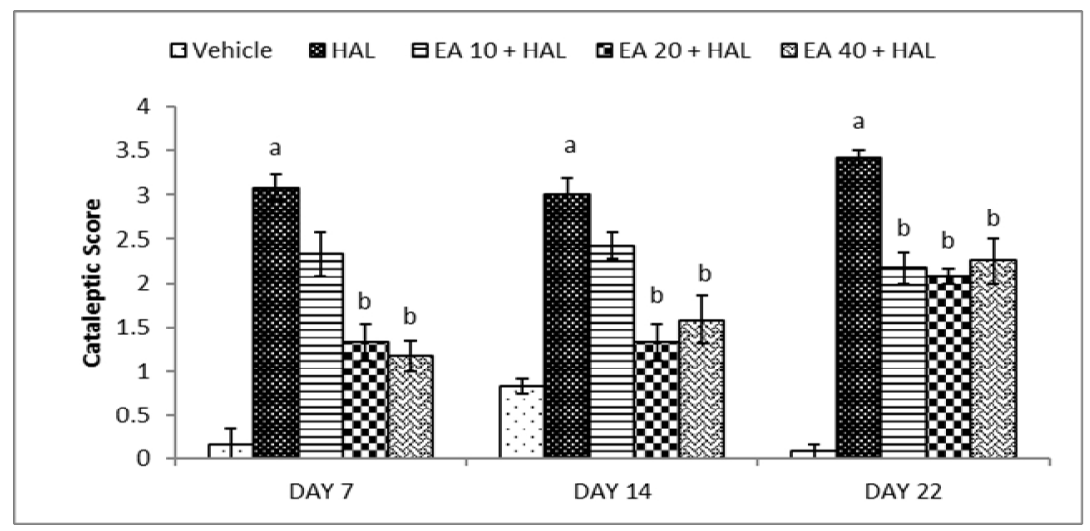

Figure 3: Effect of ellagic acid on haloperidol-induced catalepsy in rats

$n=6$ each group. Values are expressed as the mean \pm SEM. Data were analyzed by using one-way ANOVA followed by Tukey's multiple comparison test.

$F(4,25)$, Day 7=34.17; Day 14=34.53; Day 22 $=65 . \mathrm{p}<0.05 .{ }^{\mathrm{a}} \mathrm{p}<0.001$ as compared to vehicle treated control, ${ }^{\mathrm{b}} \mathrm{p}<0.001$ as compared to haloperidol treated group. HAL stands for haloperidol; EA stands for ellagic acid.

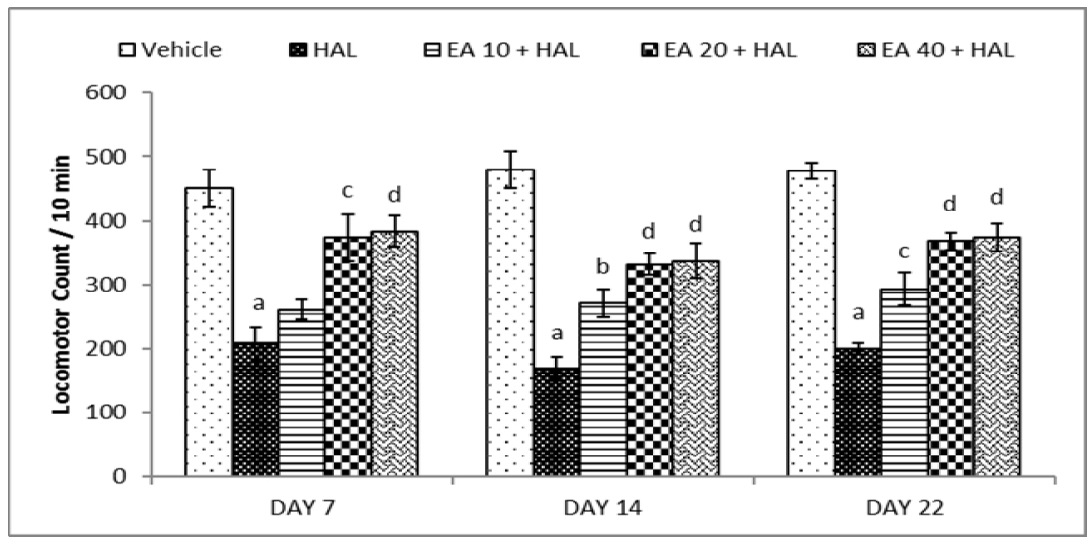

Figure 4: Effect of ellagic acid on locomotor activity of rats using actophotometer

$\mathrm{n}=6$ each group. Values are expressed as the mean \pm SEM. Data were analyzed by using one-way ANOVA followed by Tukey's multiple comparison test.

$F(4,25)$, Day 7=13.69; Day 14=24.08; Day 22=34.53. $\mathrm{p}<0.05 .{ }^{\mathrm{a}} \mathrm{p}<0.001$ as compared to vehicle treated control, ${ }^{\mathrm{b}} \mathrm{p}<0.05,{ }^{\mathrm{c}} \mathrm{p}<0.01$ and ${ }^{\mathrm{d}} \mathrm{p}<0.001$ as compared to haloperidol treated group. HAL stands for haloperidol; EA stands for ellagic acid.

\section{RESULTS}

Effect of ellagic acid on haloperidol-induced VCMs and tongue protrusion

Haloperidol (1 $\mathrm{mg} / \mathrm{kg}$, ip) treatment significantly increased VCMs and tongue protrusion in rats on day 7,14 and 22 as compared to respective vehicle treated control. Ellagic acid (20 and $40 \mathrm{mg} / \mathrm{kg}$, po) significantly reversed haloperidol-induced VCMs and tongue protrusion on day 7, 14 and 22 as compared to respective haloperidol treated animals. The lowest dose of ellagic acid $(10 \mathrm{mg} / \mathrm{kg})$ did not significantly reverse haloperidolinduced $\mathrm{VCMs}$ on $7^{\text {th }}$ day, but significantly reversed haloperidol-induced VCMs on $14^{\text {th }}$ day and $22^{\text {nd }}$ day. Ellagic acid $(10 \mathrm{mg} / \mathrm{kg})$ significantly decreased haloperidol-induced tongue protrusion on $7^{\text {th }}, 14^{\text {th }}$ and $22^{\text {nd }}$ days (Figure 1 and 2).

Effect of ellagic acid on haloperidol-induced catalepsy in rats

Haloperidol (1 $\mathrm{mg} / \mathrm{kg}$, ip) treatment significantly increased cataleptic scores of rats on day 7,14 and 22 as compared to respective vehicle treated control. Ellagic acid (20 and 40 $\mathrm{mg} / \mathrm{kg}$, po) administered for 21 successive days significantly reversed haloperidol-induced catalepsy. But the lowest dose (10 $\mathrm{mg} / \mathrm{kg}$ ) of ellagic acid significantly reversed haloperidolinduced catalepsy on day 22 only (Figure 3).

Effect of ellagic acid on haloperidol-induced decrease in locomotor activity of rats

Haloperidol (1 mg/kg, ip) treatment significantly decreased the locomotor activity of rats on day 7,14 and 22 as compared to respective vehicle treated control. Ellagic acid (20 and 40 $\mathrm{mg} / \mathrm{kg}$, po) significantly reversed haloperidol-induced decrease in locomotor activity of rats after 7,14 and 21 days of treatment. The lowest dose $(10 \mathrm{mg} / \mathrm{kg})$ of ellagic acid did not show significant increase in locomotor count on $7^{\text {th }}$ and $14^{\text {th }}$ days, but significantly reversed haloperidol-induced decrease in locomotor activity of rats after 21 days of treatment (Figure 4).

Effect of ellagic acid on haloperidol-induced changes in brain dopamine and serotonin levels

Haloperidol significantly decreased dopamine and serotonin levels in rat brain. Whereas, ellagic acid (all the 3 doses) significantly reversed haloperidol-induced decrease in brain dopamine and serotonin levels (Table 1). 


\section{DISCUSSION}

In the present study, chronic administration of ellagic acid significantly inhibited haloperidol-induced orofacial dyskinesia and catalepsy as compared to vehicle-treated control. Haloperidol-induced orofacial dyskinesia model is widely employed model in rodents to predict anti-tardive dyskinetic potential of drugs ${ }^{8}, 29$. Haloperidol $(1 \mathrm{mg} / \mathrm{kg}$, ip) produced significant increase in VCMs and tongue protrusions in rats, indicating induction of orofacial dyskinesia. Haloperidol also significantly produced catalepsy in rats. Catalepsy in animals shares similarities with Parkinson's disease in humans. Antipshychotic drugs induce catalepsy by decreased dopamine transmission at dopamine $\mathrm{D}_{2}$ receptors ${ }^{30}, 31$. Ellagic acid administered for 21 successive days significantly reversed haloperidol-induced catalepsy in rats.

The dopamine system has also been regarded crucial in controlling motor activity ${ }^{32}$. In the present study, haloperidol significantly decreased locomotor activity of rats. Dopamine receptor supersenstivity might be responsible for decrease in locomotor activity by haloperidol ${ }^{25}$. Ellagic acid administered for 21 successive days significantly reversed haloperidol induced-decrease in locomotor activity.

Chronic administration of haloperidol also significantly decreased dopamine and serotonin levels in forebrain as compared to vehicle treated control, which is also supported by the literature ${ }^{29}$. Ellagic acid administered for 21 successive days significantly restored the decreased levels of brain dopamine and serotonin. Chronic haloperidol administration produces dopamine supersensitivity which may increase the number of dormant receptors and this result in decrease in levels of dopamine in brain extracellular spaces. Accumulation of haloperidol metabolites in brain resulting after chronic haloperidol administration, may lead to the death of dopaminergic neurons. Also, quinone species formation is responsible for decrease in dopamine levels. It is well reported that after chronic administration of haloperidol, there is increase in dopamine and nor-adrenaline receptor density ${ }^{6,7}$. Ellagic acid has been reported to possess antioxidant activity ${ }^{16,22}$, which might prevent formation of quinone species and death of dopaminergic neurons. The serotonergic system plays a role in inhibitory modulation of activity of dopaminergic neurons ${ }^{33}$. The decrease in serotonin levels in rat brain after chronic administration of haloperidol is in line with the literature ${ }^{25,29}$. Ellagic acid dose dependently prevented this depletion of serotonin in brain.

Typical neuroleptics including haloperidol, mostly act by blocking dopamine $\mathrm{D}_{2}$ receptors and result in increased dopamine turnover. This may conceivably result in increased hydrogen peroxide production and other toxic metabolites of dopamine, resulting in increased oxidative stress. So, the compounds possessing potent antioxidant and neuroprotective properties could be possible candidates for treating this hyperkinetic disorder ${ }^{8}$. Since ellagic acid has been reported to possess antioxidant activity $^{16}, 18,34$ which might also be responsible for its anti-tardive dyskinesia effect.

\section{CONCLUSION}

In conclusion, ellagic acid significantly reversed haloperidolinduced tardive dyskinesia and catalepsy in rats probably through increase in brain dopamine and serotonin levels; and also through its antioxidant activity. Therefore, ellagic acid may be explored further for its potential in the management of neuroleptic-induced tardive dyskinesia and Parkinsonism.

\section{Abbreviations}

VCMs - Vacuous chewing movements; po - per oral; ip intraperitoneal

\section{REFERENCES}

1. Diagnostic and statistical manual of mental disorders, 4th ed., Text Revision (DSM-IV-TR) Washington DC: American Psychiatric Association. 2000. p. 803-5.

2. Raja M. Tardive dystonia: prevalence, risk factors and comparison with tardive dyskinesia in a population of two hundred acute psychiatric in patients. Eur Arch Psychiatry Clin Neurosci 1995; 245: 145-51.

3. Subramaniam B, Rollema H, Woolf T, Castagnoli NG. Identification of a potentially neurotoxic pyridinium metabolite of haloperidol in rats. Biochem Biophys Res Commun 1990; 166: 238- 44.

4. Sagara Y. Induction of reactive oxygen species in neurons by haloperidol. J Neurochem 1998; 71: 1002-12.

5. Andreassen AO, Jørgensen HA. Neurotoxicity associated with neuroleptic-induced oral dyskinesia in rats. Prog Neurobiol 2000; 61: 525-41.

6. Seeman P. Targeting the dopamine $\mathrm{D}_{2}$ receptor in schizophrenia. Expert Opin Ther Targets 2006; 10(4): 51531.

7. Kulkarni SK, Naidu PS. Animal models of tardive dyskinesia-A review. Indian J Physiol Pharmacol 2001; 45(2): 148-60.

8. Naidu PS, Singh A, Kulkarni SK. Quercetin, a bioflavonoid attenuated haloperidol induced orofacial dyskinesia. Neuropharmacol 2003; 44: 1100-6.

9. Reckziegel P, Peroza LR, Schaffer LF, Ferrari MC, de Freitas CM, Bürger ME, et al. Gallic acid decreases vacuous chewing movements induced by reserpine in rats. Pharmacol Biochem Behav 2013; 104: 132-7.

10. Soares KV, McGrath JJ. Vitamin E for neuroleptic-induced tardive dyskinesia. Cochrane Database Syst Rev 2001; 4 CD000209.

11. Shamir E, Barak Y, Shalman I, Laudon M, Zisapel N, Tarrasch R, et al. Melatonin treatment for tardive dyskinesia: a double-blind, placebo-controlled, crossover study. Arch Gen Psychiatry 2001; 58: 1049-52.

12. Lister J, Nobrega JN, Fletcher PJ, Remington G. Oxidative stress and the antipsychotic-induced vacuous chewing movement model of tardive dyskinesia: evidence for antioxidant-based prevention strategies. Psychopharmacol 2014; 231: 2237-49.

13. Luo W, Zhao M, Yang B, Shen G, Rao G. Identification of bioactive compounds in Phyllanthus emblica L. fruit and their free radical scavenging activities. Food Chem 2009; 114: 499-504.

14. Kwak HM, Jeon SY, Sohng BH, Kim JG, Lee JM, Lee KB, et al. beta-Secretase (BACE1) inhibitors from pomegranate (Punica granatum) husk. Arch Pharm Res 2005; 28: 132832.

15. Loren DJ, Seeram NP, Schulman RN, Holtzman DM. Maternal dietary supplementation with pomegranate juice is neuroprotective in an animal model of neonatal hypoxicischemic brain injury. Pediatr Res 2005; 57: 858-64.

16. Dhingra D, Chhillar R. Antidepressant-like activity of ellagic acid in unstressed and acute immobilization-induced stressed mice. Pharmacol Rep 2012; 64: 796-807. 
17. Dhingra D, Jangra A. Antiepileptic activity of ellagic acid, a naturally occurring polyphenolic compound, in mice. J Funct Foods 2014; 10: 364-9.

18. Kaur R, Mehan S, Khanna D, Kalra K. Ameliorative treatment with ellagic Acid in scopolamine induced Alzheimer's type memory and cognitive dysfunctions in rats. Austin J Clin Neurol 2015; 2(6): 1053.

19. Feng Y, Yang SG, Du XT, Zhang X, Sun XX, Zhao M, et al. Ellagic acid promotes Ab42 fibrillization and inhibits amyloid beta 42-induced neurotoxicity. Biochem Biophys Res Commun 2009; 390: 1250-4.

20. Dolatshahi M, Farbood Y, Sarkaki A, Mansouri SMT, Khodadadi A. Ellagic acid improves hyperalgesia and cognitive deficiency in 6-hydroxidopamine induced rat model of Parkinson's disease. Iran J Basic Med Sci 2015; 18: 38-46.

21. Rafieirad M, Allahbakhshi E, Nezhad ZZ. Neuroprotective effects of oral ellagic acid on locomotor activity and anxiety-induced by ischemia/hypoperfusion in rat. Adv Environ Biol 2014; 8(1): 83-8.

22. Uzar E, Alp H, Cevik MU, Firat U, Evliyaoglu O, Tufek A, et al. Ellagic acid attenuates oxidative stress on brain and sciatic nerve and improves histopathology of brain in streptozotocin-induced diabetic rats. Neurol Sci 2012; 33: 567-74.

23. Dhingra D and Gahalain N. Protective effect of ellagic acid against reserpine-induced orofacial dyskinesia and oxidative stress in rats. Pharmacologia 2016; 7: 16-21.

24. Gordon JH, Borison RL, Diamond BI. Estrogen in experimental tardive dyskinesia. Neurol 1980; 30(5): 5514.

25. Bishnoi M, Chopra K, Kulkarni SK. Protective effect of curcumin, the active principle of turmeric (Curcuma longa) in haloperidol-induced orofacial dyskinesia and associated behavioural, biochemical and neurochemical changes in rat brain. Pharmacol Biochem Behav 2008; 88: 511-22.

26. Celik G, Semiz A, Karakurt S, Arslan S, Adali O, Sen A. A comparative study for the evaluation of two doses of ellagic acid on hepatic drug metabolizing and antioxidant enzymes in the rat. Biomed Res Int 2013; 2013:358945. doi: $10.1155 / 2013 / 358945$

27. Kulkarni SK. Practical pharmacology and clinical pharmacy. Delhi: Vallabh Prakashan; 2008. p. 131-33.

28. Schlumpf M, Lichtensteiger W, Langemann H, Waser PG, Hefti F. A fluorimetric micromethod for the simultaneous determination of serotonin, noradrenaline and dopamine in milligram amount of brain tissue. Biochem Pharmacol 1974; 23: 2337-446.

29. Bishnoi M, Chopra K, Kulkarni SK. Neurochemical changes associated with chronic administration of typical antipsychotics and its relationship with tardive dyskinesia. Methods Find Exp Clin Pharmacol 2007; 29(3): 211-6.

30. Klemm WR. Neuroleptic-induced catalepsy: a $\mathrm{D}_{2}$ blockade phenomenon? Pharmacol Biochem Behav 1985; 23: 911-5.

31. Wadenberg ML, Kapur S, Soliman A, Jones C, Vaccarino F. Dopamine $\mathrm{D}_{2}$ receptor occupancy predicts catalepsy and the suppression of conditioned avoidance response behavior in rats. Psychopharmacology (Berl) 2000; 150: 422-9.

32. Clausing P, Gough B, Holson RR, Slikker WJr, Bowyer JF. Amphetamine levels in brain microdialysate, caudate/putamen, substantia nigra and plasma after dosage that produces either behavioral or neurotoxic effects. J Pharmacol Exp Ther 1995; 274(2): 614-21.

33. Sandyk R, Fisher H. Serotonin in involuntary movement disorders. Int J Neurosci 1988; 42: 185-205.

34. Türk G, Sönmez M, Ceribaşi AO, Yüce A, Ateşşahin A. Attenuation of cyclosporine-A induced testicular and spermatozoa damages associated with oxidative stress by ellagic acid. Int Immunopharmacol 2010; 10: 177-182.

\section{Cite this article as:}

Dinesh Dhingra*, Nidhi Gahalain. Amelioration of haloperidolinduced orofacial dyskinesia and catalepsy by ellagic acid in rats. Int. J. Res. Ayurveda Pharm. Mar - Apr 2016;7(Suppl 2):222-227 http://dx.doi.org/10.7897/2277-4343.07292

Disclaimer: IJRAP is solely owned by Moksha Publishing House - A non-profit publishing house, dedicated to publish quality research, while every effort has been taken to verify the accuracy of the content published in our Journal. IJRAP cannot accept any responsibility or liability for the site content and articles published. The views expressed in articles by our contributing authors are not necessarily those of IJRAP editor or editorial board members. 